in vivo $34: 3029-3032(2020)$

doi:10.21873/invivo.12136

\title{
Clinical Study of Hyperglycemia and SARS-CoV-2 Infection in Intensive Care Unit Patients
}

\author{
IOANNIS ILIAS $^{1}$, EDISON JAHAJ ${ }^{2}$, STYLIANOS KOKKORIS ${ }^{2}$, DIMITRIOS ZERVAKIS ${ }^{2}$, \\ PRODROMOS TEMPERIKIDIS ${ }^{2}$, ELENI MAGIRA ${ }^{2}$, MARIA PRATIKAKI ${ }^{2}$, ALICE G. VASSILIOU ${ }^{2}$, \\ CHRISTINA ROUTSI $^{2}$, ANASTASIA KOTANIDOU ${ }^{2}$ and IOANNA DIMOPOULOU ${ }^{2}$ \\ ${ }^{1}$ Department of Endocrinology, Diabetes and Metabolism, Elena Venizelou Hospital, Athens, Greece; \\ ${ }^{2} 1^{\text {st }}$ Department of Critical Care \& Pulmonary Services, Medical School, \\ National \& Kapodistrian University of Athens, Evangelismos Hospital, Athens, Greece
}

\begin{abstract}
Background/Aim: Reports indicate that coronaviridae may inhibit insulin secretion. In this report we aimed to describe the course of glycemia in critically ill patients with severe acute respiratory syndrome coronavirus-2 (SARS-CoV-2) infection. Patients and Methods: We studied 36 SARS-CoV-2 patients (with no history of diabetes) in one intensive care unit (ICU). All the patients were admitted for hypoxemic respiratory failure; all but four required mechanical ventilation. The mean $( \pm S D)$ age of the patients was 64.7 (9.7) years; 27 were men; the mean $( \pm S D)$ duration of ICU stay was 12.9 (8.3 days). Results: Twenty of 36 patients presented with hyperglycemia; brief intravenous infusions of short-acting insulin were administered in six patients. As of May 29 2020, 11 patients had died (seven with hyperglycemia). In 17 patients the Hyperglycemia Index [HGI; defined as the area under the curve of (hyper)glycemia level*time $(h)$ divided by the total time in the ICU] was $<16.21 \mathrm{mg} / \mathrm{dl}(0.90 \mathrm{mmol} / \mathrm{l})$, whereas in three patients the HGI was $\geq 16.21 \mathrm{mg} / \mathrm{dl}(0.90 \mathrm{~mol} / \mathrm{l})$ and $<32.25 \mathrm{mg} / \mathrm{dl}$ (1.79 mmol/l). Conclusion: In our series of ICU patients with SARS-CoV-2 infection, and no history of diabetes, a substantial number of patients had hyperglycemia, to a higher degree than would be expected by the stress of critical illness, lending credence to reports that speculated a tentative association between SARS-CoV-2 and hyperglycemia. This finding is important, since hyperglycemia can lead to further infectious complications.
\end{abstract}

This article is freely accessible online.

Correspondence to: Ioannis Ilias, Department of Endocrinology, Diabetes and Metabolism, Elena Venizelou Hospital, 2, Elena Venizelou Square, Athens GR-11521, Greece. Tel: +30 2132051389, Fax: +30 2106465559, email: iiliasmd@yahoo.com

Key Words: Coronaviridae, severe acute respiratory syndrome, intensive care units, hyperglycemia, human.
Coronaviridae [such as severe acute respiratory syndrome coronavirus-1 (SARS-CoV-1) or Middle East Respiratory Syndrome coronavirus (MERS-CoV)] have been shown in experimental conditions and at the cellular level - to inhibit insulin secretion (1-3). Early reports of patients with severe acute respiratory syndrome coronavirus-2 (SARS$\mathrm{CoV}-2$ ) infection indicated that $45-52 \%$ presented with hyperglycemia, with no more than $10 \%$ having a medical history of diabetes $(4,5)$. Thus, an association of SARSCoV-2 with hyperglycemia seems plausible (1), however, other reports describing the glycemic profile of patients admitted to the intensive care units (ICU) with SARS-CoV2 are lacking. Better characterization of the glycemic profile of patients with SARS-CoV-2 infection in critically ill patients could be useful in guiding clinical decisions, since hyperglycemia may lead to further infectious complications (6). The aim of our single-center study was to describe the course of glycemia in critically ill patients with SARS-CoV-2 in one of the seven ICUs dedicated to the management of these patients in the metropolitan Athens capital area.

\section{Patients and Methods}

We included patients with laboratory-confirmed SARS-CoV-2 infection who were admitted to the Evangelismos hospital ICU in the Athens capital region between March 20 and May 3, 2020 (the largest of the seven public health system ICUs dedicated to providing care for SARS-CoV-2 patients in the region). All the patients were admitted for hypoxemic respiratory failure. The patient data were censored upon the study's cutoff, on May 29, 2020. Cases were considered as having SARS-CoV-2 infection based on positive results of reverse-transcriptase-polymerasechain-reaction (RT-PCR) assays of nasopharyngeal swab specimens; only cases with laboratory confirmation were included. Forty adults (with an age of 18 years or older) were identified. Exclusion criteria included pregnancy and prior medical history/diagnosis of any form of diabetes (to search for previous existence of diabetes we assessed physician 

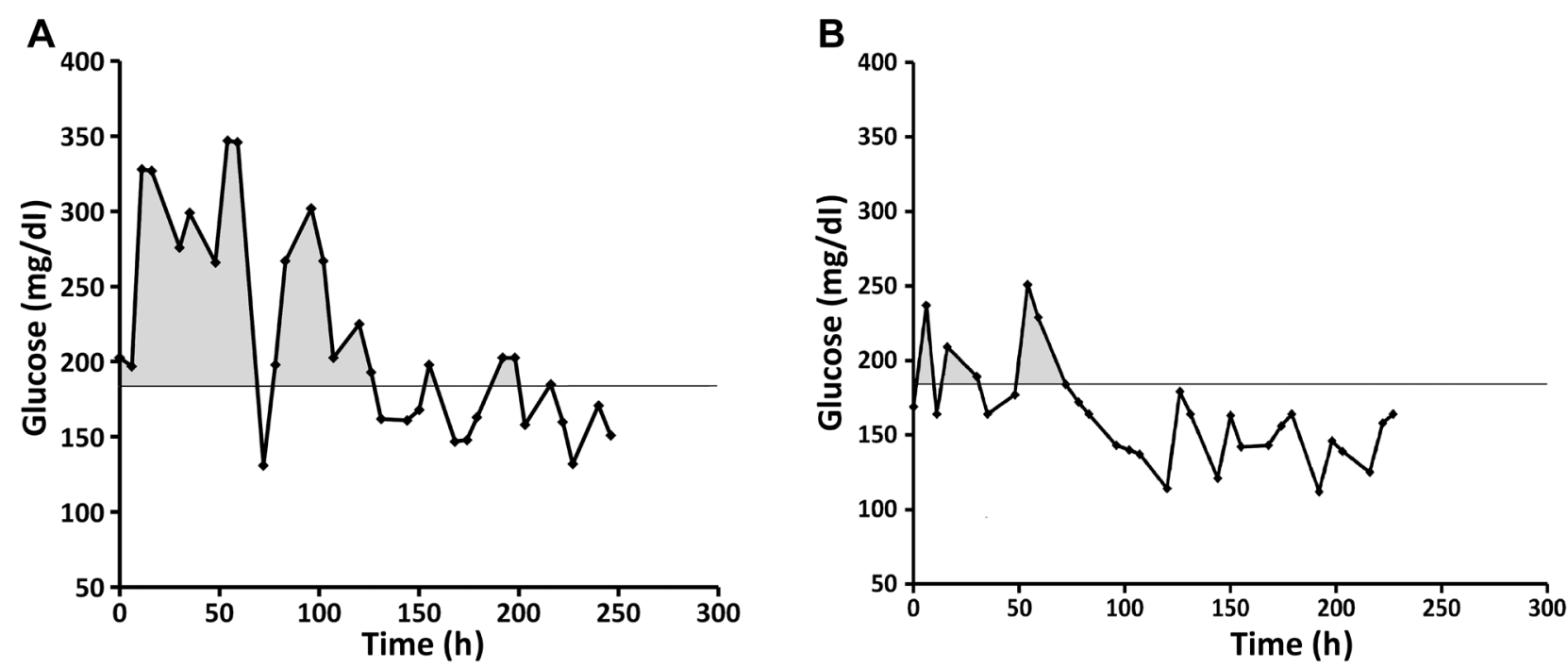

Figure 1. Graph of glucose over time during ICU hospitalization of a patient with Hyperglycemia Index (HGI) of $25.632 \mathrm{mg} / \mathrm{dl} \mathrm{or} 1.424 \mathrm{mmol} / \mathrm{l}$ (A) and of a patient with HGI: $3.376 \mathrm{mg} / \mathrm{dl}$ or $0.187 \mathrm{mmol} / \mathrm{l}(B)$; the HGI is calculated from the shaded area divided by total time in the ICU as per (7).

documentation, Hellenic National Health service electronic records and queried the patients' next of kin). The data were summarized with descriptive statistics; quantitative results are reported as means and standard deviations, while qualitative results are given as counts. The study was approved by the Scientific Council/Ethics Board of the Evangelismos Hospital (No 170/April 24, 2020); written informed consent for inclusion of anonymized data for publication was obtained from the patients or their next of kin. We excluded four patients with a medical history of diabetes and studied 36 patients (27 men; mean age $\pm \mathrm{SD}=64.7 \pm 9.7$ years) for up to 10 days. Their mean $\pm \mathrm{SD}$ admission APACHE and SOFA scores were $16 \pm 4$ and $8 \pm 2$, respectively. Eighteen patients were obese $\left(B M I>30 \mathrm{~kg} / \mathrm{m}^{2}\right), 13$ were smokers, 16 were treated for hypertension, six were treated for hyperlipidemia, one was on levothyroxine supplementation for hypothyroidism; ten patients had more than one coexisting condition. Admission data are presented in Table I. All the patients upon admission had imaging studies (CT scan) showing bilateral pulmonary opacities (ground glass) and hypoxemia (mean $\pm \mathrm{SD} \mathrm{PaO} / \mathrm{FIO}_{2}$ was $160 \pm 67$ ). Thirty-two patients received mechanical ventilation. Twenty-seven patients received antiviral therapy (lopinavir) and 24 received hydroxychloroquine and azithromycin; 21 received inotropes.

Blood glucose was measured upon admission and thereafter for three times per day (at approximately 07:00, 14:00 and 20:00). Overall, more than 1.000 blood glucose measurements were analyzed. During ICU hospitalization target glycemia was set between $110-179 \mathrm{mg} / \mathrm{dl}(6.10-9.93 \mathrm{mmol} / \mathrm{l})$. Hyperglycemia $>180$ $\mathrm{mg} / \mathrm{dl}(10.00 \mathrm{mmol} / \mathrm{l})$ was evaluated over time by calculating the Hyperglycemia Index [HGI; defined as the area under the curve of (hyper)glycemia level*time (hours) divided by the total time in the ICU] (Figure 1) (7). Statistical analysis for the frequency of hyperglycemia was done with the one-sample Chi square test, assuming an expected frequency of hyperglycemia of $25 \%(n=9)$, $33 \%(\mathrm{n}=12)$ or $50 \%(\mathrm{n}=18)$.
Table I. Data of patients $(n=36)$ upon ICU admission.

\begin{tabular}{lc}
\hline Temperature $\left({ }^{\circ} \mathrm{C}\right)$ & $36.9 \pm 1.4$ \\
Heart rate $(\mathrm{bpm})$ & $84 \pm 27$ \\
Respiratory rate $($ per minute) & $23 \pm 3$ \\
White blood cell count $($ per $\mu \mathrm{l})$ & $5200 / 9800 / 12425$ \\
Lymphocytes $(\%)$ & $8 / 13 / 18$ \\
Hemoglobin $(\mathrm{g} / \mathrm{dl})$ & $12.5 \pm 2.1$ \\
Platelets $($ per $\mu \mathrm{l})$ & $129750 / 190000 / 254250$ \\
Creatinine $(\mathrm{mg} / \mathrm{dl})$ & $0.8 / 1.0 / 1.2$ \\
Aspartate aminotransferase $(\mathrm{U} / \mathrm{l})$ & $28 / 42 / 57$ \\
Alanine aminotransferase $(\mathrm{U} / \mathrm{l})$ & $22 / 37 / 49$ \\
Total bilirubin $(\mathrm{mg} / \mathrm{dl})$ & $0.5 / 0.6 / 0.8$ \\
\hline
\end{tabular}

Values are means \pm standard deviations or quartiles.

\section{Results}

Twenty out of 36 patients had hyperglycemia; in 17 patients the HGI was $<16.21 \mathrm{mg} / \mathrm{dl}(0.90 \mathrm{mmol} / \mathrm{l})$, whereas in three patients the HGI was $\geq 16.21 \mathrm{mg} / \mathrm{dl}(0.90 \mathrm{~mol} / \mathrm{l})$ and $<32.25$ $\mathrm{mg} / \mathrm{dl}(1.79 \mathrm{mmol} / \mathrm{l})$ (Figure 1). In 16 patients blood glucose did not exceed $179 \mathrm{mg} / \mathrm{dl}(9.93 \mathrm{mmol} / \mathrm{l})$. The observed frequency of hyperglycemia was statistically significant for expected frequencies of hyperglycemia of $25 \%$ or $33 \%$ but not for $50 \%$ (Chi-squared $=17.926,8.000$ and 0.444 and $p=0.0002,0.0004$ and 0.505 , respectively). Hyperglycemia was treated with brief intravenous infusion of short-acting insulin in six patients.

As of May 29 2020, 11 of the patients had died (seven with hyperglycemia; mean \pm SD duration of ICU stay was $13.2 \pm 12.2$ days), seven were receiving mechanical 
ventilation and were still in the ICU and 18 had been discharged from the ICU after 8.3 \pm 6.6 days.

\section{Discussion}

Twenty-five percent of critically ill patients with no history of diabetes have stress hyperglycemia (the underlying endogenous mechanisms may include the release of counterregulatory hormones, alteration of insulin receptor signaling due to inflammation and inhibition of pancreatic beta-cell function) (8). In our series of ICU patients with SARS-CoV2 , and no history of diabetes, a substantial number of patients had hyperglycemia, corroborating the findings from the early phases of the SARS-CoV-2 pandemic in China, where approximately half of the hospitalized patients were noted to have hyperglycemia $(4,5)$. Hyperglycemia was also noted in some non-diabetic patients in a series of SARS-CoV-2 patients from the United States; in this series admission hyperglycemia was associated with chest imaging findings (9).

Coronaviridae such as SARS-CoV-1 or MERS-CoV, have been shown to cause failure of the islets of Langerhans and activation of dipeptidyl peptidase 4 (DPP4), respectively, thus inhibiting insulin secretion; SARS-CoV-2- may also provoke hyperglycemia (the mechanisms are not elucidated yet) (1-3). Thus, our findings may lend credence to reports that showed hyperglycemia in patients with SARS-CoV-2 infection (mostly with diabetes but also without diabetes) and speculated a tentative association between SARS-CoV2 and hyperglycemia $(1,4,5,10)$.

This is possibly the largest - to date - study on glycemia in critically ill non-diabetic patients with SARS-CoV-2 infection. There are caveats in our study: sample size could be considered to be low and there was no control group for proper comparisons (however, for expected frequencies of $25 \%$ or $33 \%$ with $\alpha=0.05$, the post hoc power of the study was calculated to be $97 \%$ or $79 \%$, respectively). Continuous glucose monitoring (CGM) would also be helpful, providing more complete and dynamic data of glycemia over time. Additionally, another factor modulating glycemia might have been the administration of hydroxychloroquine. The latter has been shown to increase the sensitivity to insulin $(11,12)$. Thus, a possible effect of SARS-CoV-2 on glycemia might have been suppressed, as therapeutic levels of hydroxychlo-roquine increased. The study of new-onset hyperglycemia in nondiabetic patients with SARS-CoV-2 infection is an active field of research and worldwide relevant data are currently being gathered, especially with the ongoing CoviDIAB Project (13).

\section{Conclusion}

In our series of ICU patients with SARS-CoV-2, and no history of diabetes, a substantial number of patients had hyperglycemia, to a higher degree than would be expected by the stress of critical illness. This finding lends credence to reports that have speculated a tentative association between SARS-CoV-2 infection and hyperglycemia, by - yet - undefined mechanisms. This new-onset hyperglycemia may be clinically important, since it can lead to further infectious complications.

\section{Data Availability}

The anonymized data for this report are available upon request to the Authors.

\section{Conflicts of Interest}

The Authors have no conflicts of interest to report.

\section{Authors' Contributions}

All Authors collected data and prepared the article; statistical analysis was done by II and ID.

\section{Acknowledgements}

Research for this report did not receive specific funding, but was performed as part of the employment of the authors at Evangelismos Hospital and Elena Venizelou Hospital, Athens, Greece.

\section{References}

1 Ilias I and Zabuliene L: Hyperglycemia and the novel covid-19 infection: Possible pathophysiologic mechanisms. Med Hypotheses 139: 109699, 2020. PMID: 32240876. DOI: 10.1016/j.mehy. 2020.109699

2 Yang JK, Lin SS, Ji XJ and Guo LM: Binding of sars coronavirus to its receptor damages islets and causes acute diabetes. Acta Diabetol 47: 193-199, 2010. PMID: 19333547. DOI: $10.1007 / \mathrm{s} 00592-009-0109-4$

3 Kleine-Weber H, Schroeder S and Kruger N: Polymorphisms in dipeptidyl peptidase 4 reduce host cell entry of middle east respiratory syndrome coronavirus. Emerg Microbes Infect 9: 155-168, 2020. PMID: 31964246. DOI: 10.1080/22221751. 2020.1713705

4 Wu C, Chen X, Cai Y, Xia J, Zhou X, Xu S, Huang H, Zhang L, Du C, Zhang Y, Song J, Wang S, Chao Y, Yang Z, Xu J, Chen D, Xiong W, Xu L, Zhou F, Jiang J, Bai C, Zheng J and Song Y: Risk factors associated with acute respiratory distress syndrome and death in patients with coronavirus disease 2019 pneumonia in Wuhan, China. JAMA Intern Med: e200994, 2020. PMID: 7070509. DOI: 10.1001/jamainternmed.2020.0994

5 Chen N, Zhou M, Dong X, Qu J, Gong F, Han Y, Qiu Y, Wang J, Liu Y, Wei Y, Xia J, Yu T, Zhang X and Zhang L: Epidemiological and clinical characteristics of 99 cases of 2019 novel coronavirus pneumonia in wuhan, china: A descriptive study. Lancet 395(10223): 507-513, 2020. PMID: 7135076. DOI: 10.1016/s0140-6736(20)30211-7

6 Butler SO, Btaiche IF and Alaniz C: Relationship between hyperglycemia and infection in critically ill patients. 
Pharmacotherapy 25: 963-976, 2005. PMID: 16006275 . DOI: 10.1592/phco.2005.25.7.963

7 Vogelzang M, van der Horst IC and Nijsten MW: Hyperglycaemic index as a tool to assess glucose control: A retrospective study. Crit Care 8(3): R122-127, 2004. PMID: 15153239. DOI: $10.1186 / \mathrm{cc} 2840$

8 Ali Abdelhamid Y, Kar P, Finnis ME, Phillips LK, Plummer MP, Shaw JE, Horowitz M and Deane AM: Stress hyperglycaemia in critically ill patients and the subsequent risk of diabetes: A systematic review and meta-analysis. Crit Care 20(1): 301, 2016. PMID: 5039881. DOI: 10.1186/s13054-016-1471-6

9 Iacobellis G, Penaherrera CA, Bermudez LE and Bernal Mizrachi E: Admission hyperglycemia and radiological findings of sars-cov2 in patients with and without diabetes. Diabetes Res Clin Pract 164: 108185, 2020. PMID: 7251996. DOI: 10.1016/j.diabres.2020.108185

10 Sardu C, D'Onofrio N, Balestrieri ML, Barbieri M, Rizzo MR, Messina V, Maggi P, Coppola N, Paolisso G and Marfella R: Outcomes in patients with hyperglycemia affected by covid-19: Can we do more on glycemic control? Diabetes Care 43(7): 1408-1415, 2020. PMID: 32430456. DOI: 10.2337/dc20-0723
11 Dai Y, Lin G and Shi D: Hypoglycemia induced by hydroxychloroquine sulfate in a patient treated for connective tissue disease without diabetes mellitus. Clin Ther 42(5): 940-945, 2020. PMID: 32336573. DOI: 10.1016/j.clinthera.2020.03.011

12 Mercer E, Rekedal L, Garg R, Lu B, Massarotti EM and Solomon DH: Hydroxychloroquine improves insulin sensitivity in obese non-diabetic individuals. Arthritis Res Ther 14(3): R135, 2012. PMID: 3446518. DOI: 10.1186/ar3868

13 Rubino F, Amiel SA, Zimmet P, Alberti G, Bornstein S, Eckel RH, Mingrone G, Boehm B, Cooper ME, Chai Z, Del Prato S, Ji L, Hopkins D, Herman WH, Khunti K, Mbanya JC and Renard E: New-onset diabetes in Covid-19. N Engl J Med: NEJMc2018688, 2020. PMID: 7304415. DOI: 10.1056/NEJMc2018688

Received June 9, 2020

Revised June 29, 2020

Accepted June 30, 2020 